\title{
Relationship of Dexterity with Dental Caries among Subjects Having Whorl Pattern: A Dermatoglyphic Study
}

\author{
Dr. Vikram Pal Aggarwal ${ }^{1 *}$, Dr. Niharika Goyal ${ }^{2}$, Dr Manu Batra ${ }^{3}$, Dr Anmol Mathur ${ }^{4}$, \\ Dr Aditi Mathur 5 \\ ${ }^{1}$ MDS, Senior Lecturer, Department of Public Health Dentistry, Surendera Dental College and Research \\ Institute, Sri Ganganagar \\ ${ }^{2}$ Undergraduate student, Surendera Dental College and Research Institute, Sri Ganganagar \\ ${ }^{3}$ MDS, Reader, Department of Public Health Dentistry, Surendera Dental College and Research, Institute, Sri \\ Ganganagar \\ ${ }^{4}$ MDS, Reader, Department of Public Health Dentistry, Dr. D.Y Patil Vidyapeeth, Pune, Maharashtra, India \\ ${ }^{5}$ MDS, Reader, Department of Pedodontics and Preventive Dentistry, Dr. D.Y Patil Vidyapeeth, Pune, \\ Maharashtra, India
}

*Corresponding Author: Dr. Vikram Pal Aggarwal, Senior Lecturer, Department of Public Health Dentistry, Surendera Dental College and Research Institute, Sri Ganganagar., India. Email: drvikramaggarwal@yahoo.com

\begin{abstract}
Introduction: One of the most common diseases in dentistry is dental caries which has been advocated to various environmental and genetic factors. The present study was conducted to find out if there is any variation in dental caries prevalence among right and left-handed subjects having whorl pattern.

Materials and Method: The present cross-sectional study was conducted among the dentists in SriGanganagar with prior approval obtained from the Institutional Ethical Committee, before commencing the study. A total of 720 students were selected for the present study. Out of 720 students, an equal number of right (239) and lefthanded students (239) were selected. The demographic details of the students were recorded followed by fingerprint. After obtaining the fingerprints, subjects having fingerprint pattern other than whorl pattern were excluded from the study. After exclusion, 128 subjects remained in both the groups. Dental caries was recorded (according to DMFT index) in the remaining subjects with whorl pattern. Chi-square and unpaired t-test were used using SPSS 222 with the level of significance (p-value) was set at $<0.05$.
\end{abstract}

Results: Mean caries score of right-handed subjects was found to be $0.99 \pm 1.09$ whereas in left-handed subjects mean caries score was $2 \pm 2.35$ with a statistically significant difference $(<0.01)$.

Conclusion: It would be interesting to understand the relationship between the role of handedness and dermatoglyphics (with many other factors) in oral hygiene and dental care and to use this information in an effective way to prevent the occurrence of dental caries.

Keywords: Dental caries, dermatoglyphics, dexterity

\section{INTRODUCTION}

Dental caries is the most common disease in the field of dentistry. The aetiology of dental caries has been advocated to various environmental and genetic factors [1]. Previous studies [2,3,4] have approved the same that there is a correlation between dermatoglyphics and dental caries. The word "Dermatoglyphics" was coined by Cummins in 1926 [5].
It originated from two Greek words "Derma" which means skin and "Glyphics" which means carving [6]. It is a study of palmer and plantar dermal ridge carvings on hands and feet. These finger prints found in an individual are unique and remain unchanged during lifetime. Dermatoglyphics is considered for genetic correlation with dental caries as the epithelium of primary palate, and finger buds are both ectodermal in origin. Dermatoglyphics is 
therefore considered a stable marker that once formed remains same throughout a person life [1]. The epidermal ridges first appear in the form of localized cell proliferations around the 10th to 11th week of gestation. These proliferations form shallow corrugations that project into the superficial layer of the dermis. The number of ridges continue to increase, being formed either between or adjacent to existing ridges. It is during this period of primary ridge formation, that the characteristic patterns are formed. At about 14 weeks, the primary ridge formation ceases and secondary ridges begin to form as sweat gland, and develop along the apices of the primary ridges at uniform intervals. At this time, the epidermal ridges first begin to appear on the volar surfaces. The morphology of primary and secondary ridges appears as a smooth ridge of tissue and thereafter peg like structures, the dermal papillae, characteristic of the definitive dermal ridges progressively formed [6].

Authors have proved in their studies $[1,7,8,9]$ that subjects with whorl pattern showed high caries incidence. Dexterity also plays an important role in dental caries as authors in their previous studies reported that subjects who used their right hands were doing better in terms of oral hygiene than those using the left with lower prevalence of caries. [10] Along with that it was also stated in previous studies $[1,7,8,9]$ that irrespective of dexterity, the subjects with whorl pattern showed high caries prevalence.

Based upon the above information, a null hypothesis was created i.e. there will be no variation in prevalence of dental caries among right and left handed subjects having whorl pattern. Hence the present study was conducted to find out if there is any variation in dental caries prevalence among right and left handed subjects having whorl pattern.

\section{Materials AND Methodology}

The present cross sectional study was conducted among the dentists in SriGanganagar city from February 2018 to June 2018. An approval was obtained from the Institutional Ethical Committee, before commencing the study. The procedures followed were in accordance with the ethical standards of the responsible committee on human experimentation (institutional or regional) and with the Helsinki Declaration of 1975, as revised in 2000. An informed consent was obtained from the participants before oral examination and finger print recording.
A convenience sampling technique was adopted to recruit the subjects for the present study. There were 2 recognized dental colleges in Sriganganagar city. Students studying in these 2 dental colleges were recruited for the present study. There were approximately 1069 students in both the colleges. Subjects were divided according to their dexterity. Dexterity is the dominance of one hand over the other or the unequal distribution of fine motor skills between the left and right hands. Left-handedness is the predominant use of left hand over the right hand. Only those subjects were recruited in the study who gave positive consent for oral examination and finger print recording. Subjects with skin disorders, systemic disease, physical and mental incompatibility, and uncooperative patients were excluded from the study.

Randomization was done to select the subjects for the present study. In this manner a total of 720 students were selected for the present study. In general left-handedness is far less common than right-handedness. Therefore firstly subjects with left hand dominancy were selected from the total selected students i.e. 720. The left hand dominant subjects were found to be 239. After that equal number of right hand dominant subjects i.e. 239 were selected.

After explaining the purpose of the study, the demographic details of the students were recorded followed by finger print. Recording of thumb prints was done inkpad method. To avoid duplication of finger prints, the fingers were numbered from 1-5 for left little finger to the thumb, and from 6-10 for right thumb to right little finger of the hand respectively. The hands were cleaned with soap and water and then scrubbed thoroughly with an antiseptic lotion (Savlon) and allowed to dry. This was done to enhance the quality of finger prints by removing sweat $\&$ dirt from the skin surface. Duplicating ink was applied with the use of cotton applicator to all the distal phalanges of the fingerprint. Impressions were taken on a white proforma sheet with blocks for each finger. Prints were dried and studied using a magnifying lens to identify the finger patterns. The fingertip patterns were analyzed according to the classical method and configurational types [2].
1. Arch pattern
a. Simple
b. Tented
2. Whorl pattern 

Study
a. Spiral
b. Symmetrical
c. Double loop
3. Loop pattern
a. Ulnar
b. Radial.

After obtaining the fingerprints, subjects having fingerprint pattern other than whorl pattern were excluded from the study. After exclusion, 128 subjects remained in both the groups i.e. right and left hand groups. Dental caries was recorded (according to DMFT index) [11] in the remaining subjects with whorl pattern. The DMF Index is applied to the permanent dentition and is expressed as the total number of teeth or surfaces that are decayed (D), missing (M), or filled (F) in an individual. When the index is applied to teeth specifically, it is called the DMFT index, and Table1. Gender and mean age among the subjects scores per individual can range from 0 to 28 or 32 , depending on whether the third molars are included in the scoring.

\section{Statistical Analysis}

Data so collected was tabulated in an excel sheet, under the guidance of statistician. Data was analyzed using IBM SPSS. Statistics Windows, Version 22.0. (Armonk, NY: IBMCorp) for the generation of descriptive and inferential statistics. The statistical significant difference among groups was determined by unpaired test and the level of significance was set at $p<0.05$.

\section{RESULTS}

Table 1, graph 1 showed that females were dominant in both right and left handed subjects (58.59\% and $63.28 \%$ respectively). Mean age was $22.02 \pm 2.56$ in right handed subjects and $20.25 \pm 0.44$ in left handed subjects.

\begin{tabular}{|c|c|c|c|c|}
\hline \multirow[t]{2}{*}{ Variables } & \multicolumn{2}{|c|}{ Right handed } & \multicolumn{2}{|c|}{ Left handed } \\
\hline & $\mathrm{N}$ & $\%$ & $\mathrm{~N}$ & $\%$ \\
\hline \multicolumn{5}{|l|}{ Gender } \\
\hline Male & 53 & 41.41 & 47 & 36.72 \\
\hline Female & 75 & 58.59 & 81 & 63.28 \\
\hline Chi square & \multicolumn{4}{|c|}{0.78} \\
\hline $\mathrm{p}$ value & \multicolumn{4}{|c|}{0.08} \\
\hline Age in years (Mean \pm SD) & \multicolumn{2}{|c|}{$22.02 \pm 2.56$} & \multicolumn{2}{|c|}{$20.25 \pm 0.44$} \\
\hline t test & \multicolumn{4}{|c|}{1.87} \\
\hline $\mathrm{p}$ value & \multicolumn{4}{|c|}{0.24} \\
\hline
\end{tabular}

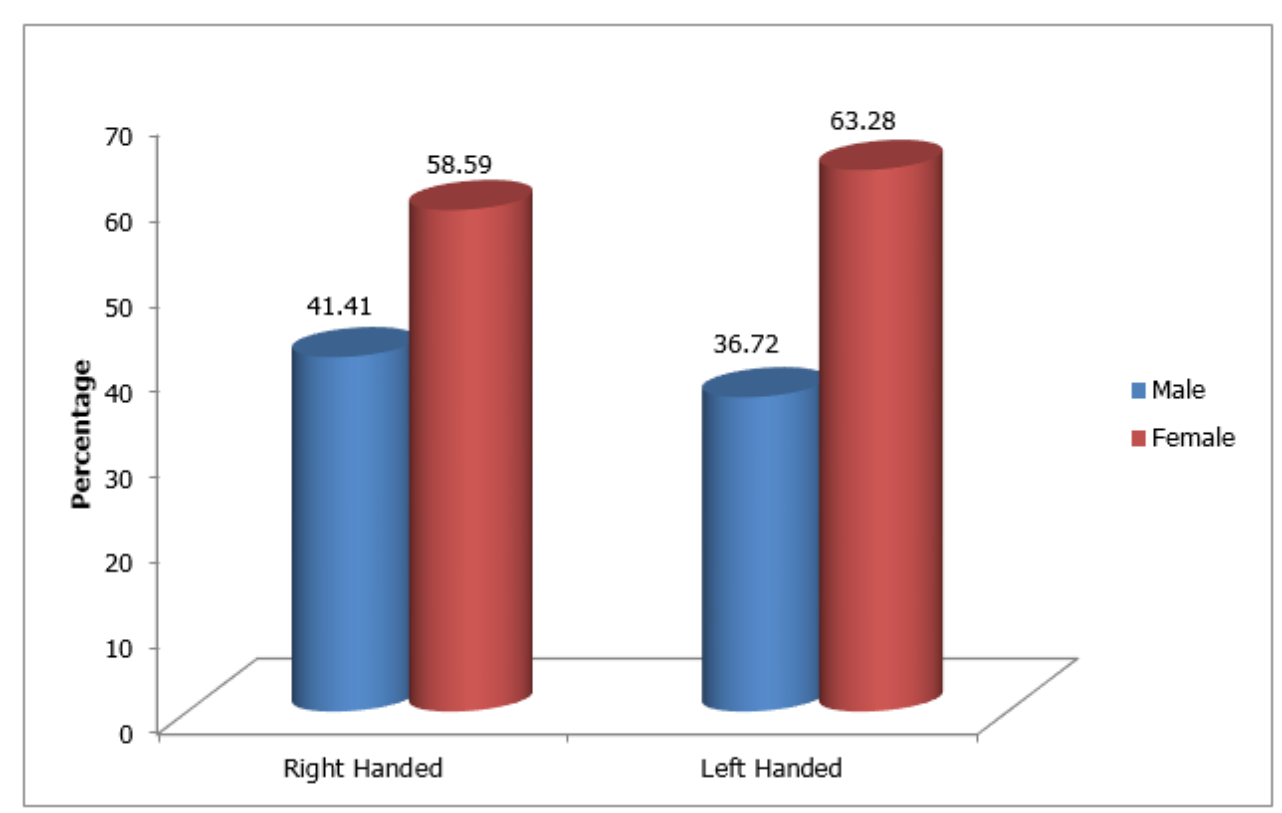

Graph1. Gender distribution among the study groups

Table 2, graph 2 showed that mean caries score of right handed subjects was found to be $0.99 \pm 1.09$ whereas in left handed subjects mean caries score was $2 \pm 2.35$.
When mean caries level was compared statistically using unpaired t test among right and left handed subjects, it was found to be statistically significant $(<0.01)$. 
Relationship of Dexterity with Dental Caries among Subjects Having Whorl Pattern: A Dermatoglyphic Study

Table2. Mean caries level among right and left handed subjects

\begin{tabular}{|c|c|c|c|c|c|c|c|}
\hline \multicolumn{2}{|c|}{ Right handed subjects } & \multicolumn{2}{l|}{ Left handed subjects } & SED & 95\% CI & t test & p value \\
\hline Mean & SD & Mean & SD & & & & \\
\hline 0.99 & 1.09 & 2 & 2.35 & 0.23 & $-1.46--0.56$ & 4.41 & $<0.01^{*}$ \\
\hline
\end{tabular}

*: statistically significant

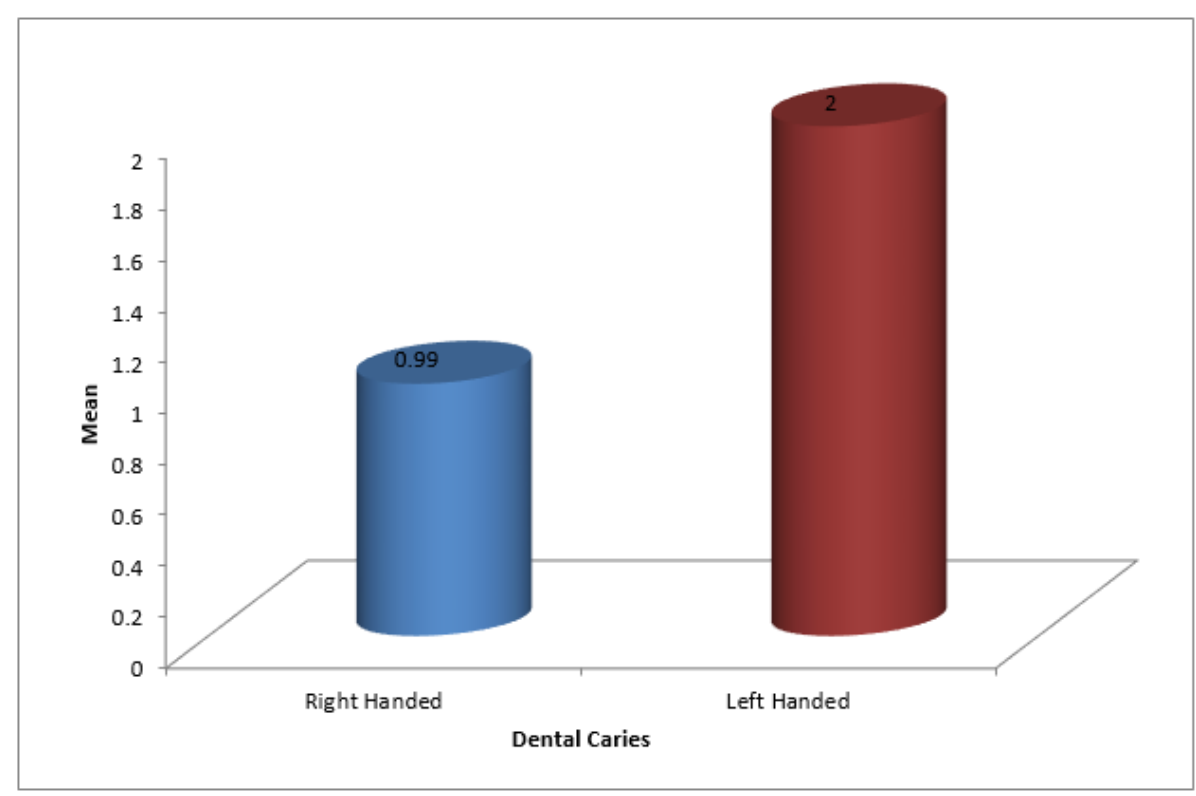

Graph2. Mean caries level among right and left handed subjects

\section{DISCUSSION}

Caries is the most common dental disease. Even with an increased focus on preventive methods, caries still emerges to be the major cause of tooth loss. There are many methods for detection of dental caries like tactile perception, lasers, and various other methods. Dermatoglyphics is one such method which helps us in the early detection of caries and whorls were found more in cariesactive cases. The present study was conducted to find out the correlation between whorl pattern and dexterity in relation to dental caries. Till now scarce literature is available on the same. Due to limited amount of data available on the topic, the present study is compared with whatever studies available.

Mean caries score in right handed subjects was $0.99 \pm 1.09$ and in left handed subjects was $2 \pm 2.35$ with statistically significant difference in the present study. The same results were reported by Cakur B et al [10] in their study.

Mean caries level differ in right and left handed subjects though both groups having whorl pattern. High caries prevalence was found in left handed subjects as compared to right handed subjects. Not only the manual dexterity but many other factors can influence dental hygiene and caries prevalence [12] including culture, socioeconomic status, life style, dietary patterns $[13,14]$, education level [14], psychological profile [15], brushing habits [16], the use of tooth paste, tooth-brushing time and the practice of correct tooth-brushing $[17,18]$, cigarette smoking [19], local and/or systemic diseases affecting oral aperture, causing xerostomia or affecting dominant upper extremity strength, motion, and dexterity $[20,21]$. These results were in contrary to the results reported by Prakruti $\mathrm{H}$. Sanghani ${ }^{1}$ and Smitha S. Shetty [4]. Therefore the results of present study rejected the null hypothesis.

Previous available literature was on the relationship between dexterity and dental caries but the present study was conducted to find out the correlation between a particular type of pattern (whorl) among right and left handed subjects to dental caries. Hence the present study finds out the relationship of dexterity with dental caries among subjects having whorl pattern. The strength of the present study is its sample size. In the present study equal number of right and left handed subjects were taken to eliminate the selection bias. Limitations of the current study is that due to cross sectional nature of the study, it did not allow assessment or track changes. Therefore further research with well-designed studies is needed for better understanding of 
between the role of handedness and dermatoglyphics in relation to dental caries.

\section{CONCLUSION}

It would be interesting to understand the relation between role of handedness and dermatoglyphics (with many other factors) in oral hygiene and dental care and to use this information in an effective way to prevent occurrence of dental caries.

\section{REFERENCES}

[1] Sanghani PH, Soni HK, Joshi MU. Correlation of dental caries and dermatoglyphics in pediatric cases. Indian J Dent Sci 2016;8:131-4.

[2] Asif SM, Lahig AR, Babu DBG. Dermatoglyphics: A Tool in Detection of Dental Caries. British J Med Med Res 2016;12(10):1-5.

[3] Deepti A, Dagrus K, Shah V, Harish M, Pateel D, Shah N. Dermatoglyphics: A Plausible Role in Dental Caries and Malocclusion? Indian J Oral Health Res 2016;2:32-5.

[4] Shetty SS, Johnli AR, Nor SNAB, Haron AB, Mohd NFB, Gunasegaram L, et al. Dermatoglyphics: A prediction tool for dental caries. International J Dent Res 2016;4(2):30-32

[5] Bhat PK, Badiyani BK, Aruna CN. Dermatoglyphics - A new diagnostic tool in detection of dental caries in children. J Indian Soc Pedod Prev Dent 2012;19:67-73.

[6] Mukherjee DP. How scientists read palms. Science Today 1980;1:15-21.

[7] Abhilash PR, Divyashree R, Patil SG, Gupta M, Chandrasekar T, Karthikeyan R. Dermatoglyphics in patients with dental caries: a study on 1250 individuals. J Contemp Dent Pract 2012;13(3):266-274.

[8] Anitha C, Konde S, Raj NS, Kumar NC, Peethamber P. Dermatoglyphics: A genetic marker of early childhood caries. J Indian Soc Pedod Prev Dent 2014;32:220-4.

[9] Singh E, Saha S, Jagannath GV, Singh S, Saha S, Garg N. Association of dermatoglyphic peculiarities with dental caries in preschool children of Lucknow, India. Int J Clin Pediatr Dent 2016;9:39-44.
[10] Cakur B, Yildiz M, Dane S, Zorba YO. The effect of right or left handedness on caries experience and oral hygiene. J Neurosci Rural Pract 2011;2:40-2.

[11] Klein H, Palmer C E, Knutson JW. Studies on dental caries i. Dental status and dental needs of elementary school children. Public health report (Wash) 1938:53:751-65.

[12] Chandra P, Anandakrishna L, Ray P. Caries experience and oral hygiene status of children suffering from attention deficit hyperactivity disorder. J Clin Pediatr Dent 2009;34:25-9.

[13] ur Rehman MM, Mahmood N, ur Rehman B. The relationship of caries with oral hygiene status and extra-oral risk factors. J Ayub Med Coll Abbottabad 2008;20:103-8.

[14] Brennan DS, Spencer AJ, Roberts-Thomson KF. Caries experience among 45-54 year olds in Adelaide, South Australia. Aust Dent J 2007;52:122-7.

[15] Gabre P. Studies on oral health in mentally retarded adults. Swed Dent J Suppl 2000;142:148.

[16] Ganss C, Schlueter N, Preiss S, Klimek J. Tooth brushing habits in uninstructed adultsfrequency, technique, duration and force. Clin Oral Investig 2009;13:203-8.

[17] Kang BH, Park SN, Sohng KY, Moon JS. Effect of a tooth-brushing education program on oral health of preschool children. J Korean Acad Nurs 2008;38:914-22.

[18] Vehkalahti MM, Paunio IK. Occurrence of root caries in relation to dental health behavior. $\mathrm{J}$ Dent Res 1988;67:911-4.

[19] Ojima M, Hanioka T, Tanaka K, Aoyama H. Cigarette smoking and tooth loss experience among young adults: A national record linkage study. BMC Public Health 2007;7:313.

[20] Poole JL, Brewer C, Rossie K, Good CC, Conte C, Steen V. Factors related to oral hygiene in persons with scleroderma. Int $\mathrm{J}$ Dent Hyg 2005;3:13-7.

[21] Pedersen TK, Gronhoj J, Melsen B, Herlin T. Condylar condition and mandibular growth during early functional treatment of children with juvenile chronic arthritis. Eur J Orthod 1995;17:385-94.

Citation: Dr. Vikram Pal Aggarwal, Dr. Niharika Goyal, Dr Manu Batra, Dr Anmol Mathur, Dr Aditi Mathur. Relationship of Dexterity with Dental Caries among Subjects Having Whorl Pattern: A Dermatoglyphic Study. ARC Journal of Dental science. 2019; 4(2):1-5. doi:dx.doi.org/ 10.20431/2456-0030. 0402001.

Copyright: () 2019 Authors. This is an open-access article distributed under the terms of the Creative Commons Attribution License, which permits unrestricted use, distribution, and reproduction in any medium, provided the original author and source are credited. 